the early healing of duodenal ulcers without significantly affecting symptoms but produces frequent severe side effects. On the evidence of this trial the use of such a high dose cannot be recommended, but if its effect on ulcer healing is still apparent at a reduced (the normal) dose with the likelihood of less pronounced side effects, then carbenoxolone may have a place in duodenal ulcer therapy.

We are grateful to Mr. H. J. Espiner, Mr. W. K. Eltringham, and $\mathrm{Mr}$. H. K. Bournes for referring patients for inclusion in the trial. We thank Dr. S. Gottfried and Biorex Laboratories for the supply of carbenoxolone and placebo capsules. P.B. acknowledges the financial help of the Medical Research Council.

\section{References}

Amure, B. O. (1970). Gut, 11, 171.

Baron, J. H., and Nabarro, J. D. N. (1968). In Symposium on Carbenoxolone Sodium, ed. J. M. Robson and F. M. Sullivan, p. 127. London, Butterworth.

Bernstein, L. M., and Baker, L. A. (1958). Gastroenterology, 34, 760

Bockus, H. L. (1963). Gastroenterology, 2nd edn., vol. 1, p. 469. Philadelphia, Saunders.

Brown, P., Salmon, P. R., and Read, A. E. (1972). Lancet," 1, 270.

Cliff, J. M., and Milton-Thompson, G. J. (1970). Gut, 11, 167

Colin-Jones, D. G., Lennard-Jones, J., Howel-Jones, J., Misiewisz, J. J., and Langman, M. J. S. (1968). In Symposium on Carbenoxolone Sodium ed. J. M. Robson and F. M. Sullivan, p. 209. London, Butterworths.
Craig, O., Hunt, T., Kimerling, J. J., and Parke, D. V. (1967). Practitioner, 199, 109.

Doll, R., Hill, I. D., Hutton, C. F., and Underwood, D. J. (1962). Lancet, $2,793$.

Doll, R., Hill, I. D., and Hutton, C. F. (1965). Gut, 6, 19.

Earlam, R. J. (1970). British Medical fournal, 4, 714.

Galloway, R. (1968). In Symposium on Carbenoxolone Sodium, ed. J. M. Robson and F. M. Sullivan, p. 203. London, Butterworths.

Hausmann, W., and Tarnoky, A. L. (1968). In Symposium on Carbenoxolone Sodium, ed. J. M. Robson and F. M. Sullivan, p. 159. London, Butterworths.

Horwich, L., and Galloway, R. (1965). British Medical fournal, 2, 1274

Hurst (formerly Hertz), A. F. (1911). The Sensibility of the Alimentary Canal. London, Oxford University Press.

Ivy, A. C., Grossman, M. I., and Bachrach, W. H. (1950). Peptic Ulcer, p. 724. London, Churchill.

Lawrence, I. H., Manton, D. J., Mendl, K., and Montgomery, R. D. (1968) In Symposium on Carbenoxolone Sodium, ed. J. M. Robson and F. M. Sullivan, p. 217. London, Butterworths.

Mitchell, A. B. S. (1971). Postgraduate Medical fournal, 47, 807.

Montgomery, R. D., Lawrence, I. H., Manton, D. J., Mendl, K., and Rowe, P. (1968). Gut, 9, 704 .

Palmer, W. L. (1926). Archives of Internal Medicine, 38, 694

Patterson, T. L., and Sandweiss, D. J. (1942). American fournal of Digestive Diseases, 9,375 .

Polland, W. S., and Bloomfield, A. L. (1931). Fournal of Clinical Investigation, $10,435$.

Ruffin, J. M., Baylis, G. J., Legerton, C. W., jun., and Tester, E. C., jun. (1953). Gastroenterology, 23, 252.

Salmon, P. R., Brown, P., Thein-Htut, and Read, A. E. (1972). Gut, 13, 170.

Smith, A. W. M. (1955). Quarterly Fournal of Medicine, 24, 393.

Talma, S. (1884). Zeitschrift für klinische Medizin, 8, 407.

Turpie, A. G. G., and Thompson, T. J. (1965). Gut, 6, 591

Wilson, M. J. (1928). Archives of Internal Medicine, 41, 633.

\title{
Effects of Haemodialysis on Bone in Chronic Renal Failure
}

\author{
M. C. BISHOP, \\ C. G. WOODS, \\ D. O. OLIVER, \\ J. G. G. LEDINGHAM, \\ R. SMITH, \\ D. A. TIBBUTT
}

British Medical fournal, 1972, 3, 664-667

\section{Summary}

Quantitative histological studies have been done on 80 sequential bone biopsies taken at yearly intervals from 37 patients with chronic renal failure on long-term haemodialysis treatment. Twenty-three patients were studied at the start of dialysis, and in about half the bone was abnormal. During dialysis mean osteoid area and the maximum number of unmineralized osteoid lamellae increased, and mineralized bone area decreased. The loss of bone during dialysis was also reflected in reduction of the width of individual trabeculae. These trends were less obvious in patients already established on dialysis at the time of the initial biopsy. The course of osteitis fibrosa appeared to be unaffected by dialysis.

\section{Nuffield Orthopaedic Centre, Oxford}

M. C. BISHOP, M.B., M.R.C.P., Research Registrar, Metabolic Unit C. G. WOODS, M.B., M.R.C.PATH., Consultant Pathologist

\section{Nuffield Departments of Medicine and Orthopaedic Surgery, University of Oxford \\ R. SMITH, M.D., M.R.C.P., First Assistant and Consultant Physician}

United Oxford Hospitals

D. A. TIBBUTT, B.M., M.R.C.P., Medical Registrar

D. O. OLIVER, M.B., M.R.C.P., Consultant Physician

J. G. G. LEDINGHAM, D.M., F.R.C.P., Consultant Physician

\section{Introduction}

Bone disease is a common complication of chronic renal failure and is not always cured by long-term haemodialysis (Pendras and Erickson, 1966; Harrison, 1968; Katz et al., 1969; Kaye et al., 1969; Kleeman et al., 1970; Siddiqui and Kerr, 1971). Before dialysis bone disease rarely causes symptoms. Radiographic appearances and plasma biochemistry are poor indices of renal osteodystrophy, particularly in dialysed patients, and diagnosis is imprecise without bone biopsy (Katz et al., 1969; Bishop, et al., 1971). Histologically there may be a combination of osteomalacia, osteitis fibrosa, and osteosclerosis (Follis and Jackson, 1943). Osteoporosis is rare (Garner and Ball, 1966; Kyle, 1969; Stanbury, 1969).

After dialysis treatment has been started the bone disorder may be similar to that affecting non-dialysed patients (Pendras, 1969). However, dialysed patients can develop a different form of disease attributed to dialysis itself (Harrison, 1968; Siddiqui and Kerr, 1971; Woods et al., 1972). In this disorder pain and unhealed pathological fractures are common; there is periarticular osteoporosis on radiography and histological examination shows a reduced volume of mineralized bone, increased osteoid, and little osteitis fibrosa (Siddiqui and Kerr, 1971). In Oxford florid bone disease in dialysed patients is rare. Histological abnormalities are more frequent (Woods et al., 1972) but less often defined by measurement of plasma calcium, phosphate, and alkaline phosphatase than in non-dialysed patients.

We have studied the histological changes in sequential bone biopsy specimens from dialysed patients from the beginning of treatment to decide whether the natural history of bone disease due to chronic renal failure hitherto described (Stanbury and Lumb, 1966) is altered by prolonged haemodialysis. 


\section{Patients and Methods}

Bone was taken by iliac crest biopsy (Williams and Nicholson, 1963) from two groups of patients with chronic renal failure. In the first group 20 out of 23 patients (aged 26-56 years) underwent biopsy before dialysis and again one year later. The remaining three patients had their first biopsy within three weeks of the start of regular dialysis treatment. In the second group 20 patients (aged 22-50 years) had the first biopsy after six months to three years on dialysis treatment and the second a year later. Thus group 2 was more heterogeneous than group 1 , but the interval between biopsies in each patient was the same. Six patients who had three sequential biopsies (at the start of dialysis and one and two years later) are included in both groups. The second biopsy in group 1 was the first in group 2 .

No patient was treated with vitamin $\mathrm{D}$ or corticosteroids, though four patients in group 2 were given oxymetholone as a measure to reduce transfusion requirements. Heparin was given during dialysis in similar priming and maintenance dosage; the estimated total dose given in any one dialysis varied between 25,000 and 35,000 IU. A single-pass Kiil system was used in which concentrate was proportioned 1:34 with softened tapwater to give a dialysate calcium concentration of about $6 \mathrm{mg} /$ $100 \mathrm{ml}$ and a magnesium concentration of $1.9 \mathrm{mg} / 100 \mathrm{ml}$. Patients had three 10-hour periods of haemodialysis each week. Most patients in group 1 were not physically active during the later stages of renal failure before dialysis, and in the early phase of dialysis treatment some were largely confined to bed. They were given day-time dialysis during the hospital training period, which varied from two to four months. Most patients in group 2 led active lives and dialysed themselves at night; they were admitted to hospital only for minor surgical procedures.

Sequential biopsy samples were taken from alternate sides of the pelvis. The histological techniques have been described elsewhere (Garner and Ball, 1966; Woods et al., 1968). Undecalcified bone sections were examined with a $\times 10$ objective for the following abnormalities.

Resorption.-Surface and dissecting resorption was identified (Woods et al., 1972) and the number of areas in which it was occurring counted.

Osteitis Fibrosa.-This was defined by profuse quantities of fibrous tissue extending from resorption cavities into the marrow space. Fibrosis confined to an area of resorption was regarded as commensurate with normal healing processes.

Osteoid.-This was identified as a series of birefringent lamellae on the surface of mineralized bone in polarized light. Osteomalacia was diagnosed if five or more lamellae were seen anywhere in the section.

\section{AREA MEASUREMENTS}

The area of mineralized bone-which is related to its volumeand osteoid were measured separately by one observer using a point-counting technique (Woods et al., 1968) on a single section. The intra-observer error was about $\pm 10 \%$ except at the lower end of the range of osteoid measurements, where the error was greater. Total bone area was estimated from the sum of osteoid and mineralized bone areas as a proportion of the total area of the section.

\section{MINIMUM TRABECULAR WIDTH}

A calibrated scale in the microscopical eyepiece was used to measure the width of the narrowest part of every trabecula in the section. Only trabeculae with osteoid or bone cells on both of the surfaces were measured.

For tests of statistical significance between area measurements and mean minimum trabecular widths on paired biopsy specimens Student's $t$ test for difference between values in matched pairs and the "sign test" for non-parametric data were used (Dixon and Massey, 1951).

\section{Results}

Group 1.-The mean osteoid area increased significantly from 0.79 to 1.19 as a percentage of the area of the section $(t=1.62$, $P<0.06$, sign test $P<0.01)$. The maximum number of osteoid lamellae also increased in most patients (Fig. 1). Two of the three patients in whom the number decreased had osteomalacia with osteitis fibrosa initially and osteitis fibrosa alone after one year of dialysis treatment. The mean area of mineralized bone fell from $20.9 \%$ to $18.3 \% \quad(t=2 \cdot 22, \mathrm{P}<0.015$, sign test $P<0 \cdot 1)$. Mean total bone area also fell from $21.7 \%$ to $19.5 \%$ $(t=1.79, \mathrm{P}<0.04)$. There was no significant trend in the change in numbers of areas of resorption. The mean minimum trabecular width fell from $91.5 \mu \mathrm{m}$ to $74.5 \mu \mathrm{m}$. The difference was highly significant $(t=5.28, P<0.0005$, sign test $\mathrm{P}<0.01)$.
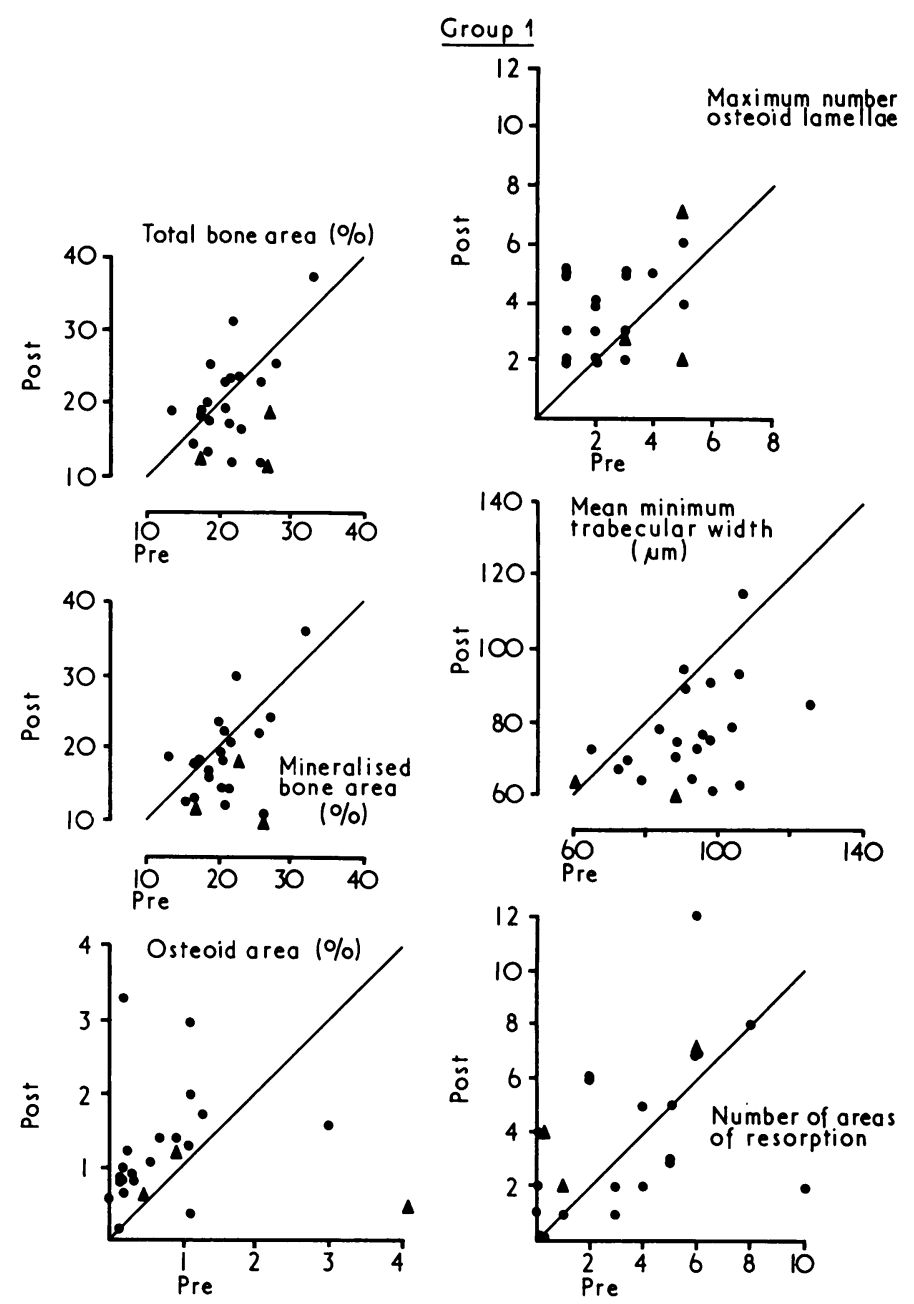

FIG. 1-Group 1. Results of bone biopsy studies before and one year after haemodialysis. Each point represents one patient. $\boldsymbol{\Delta}=$ Patients who had their first biopsy shortly after beginning dialysis.

Group 2.-In contrast to group 1 patients there were no significant changes in any of the features quantitated between the first and second biopsy specimens in group 2 patients. However, mean osteoid and mineralized bone areas in the initial samples from this group were similar to those of the second specimens in group 1 , and the maximum number of osteoid lamellae increased in most patients in group 2 (Fig. 2). Three of the four patients in whom the number decreased showed developing or persisting osteitis fibrosa. The change in number of resorptive areas was not consistent. The mean minimum trabecular width fell from $80.0 \mu \mathrm{m}$ to $77.7 \mu \mathrm{m}$. The difference was not significant. 


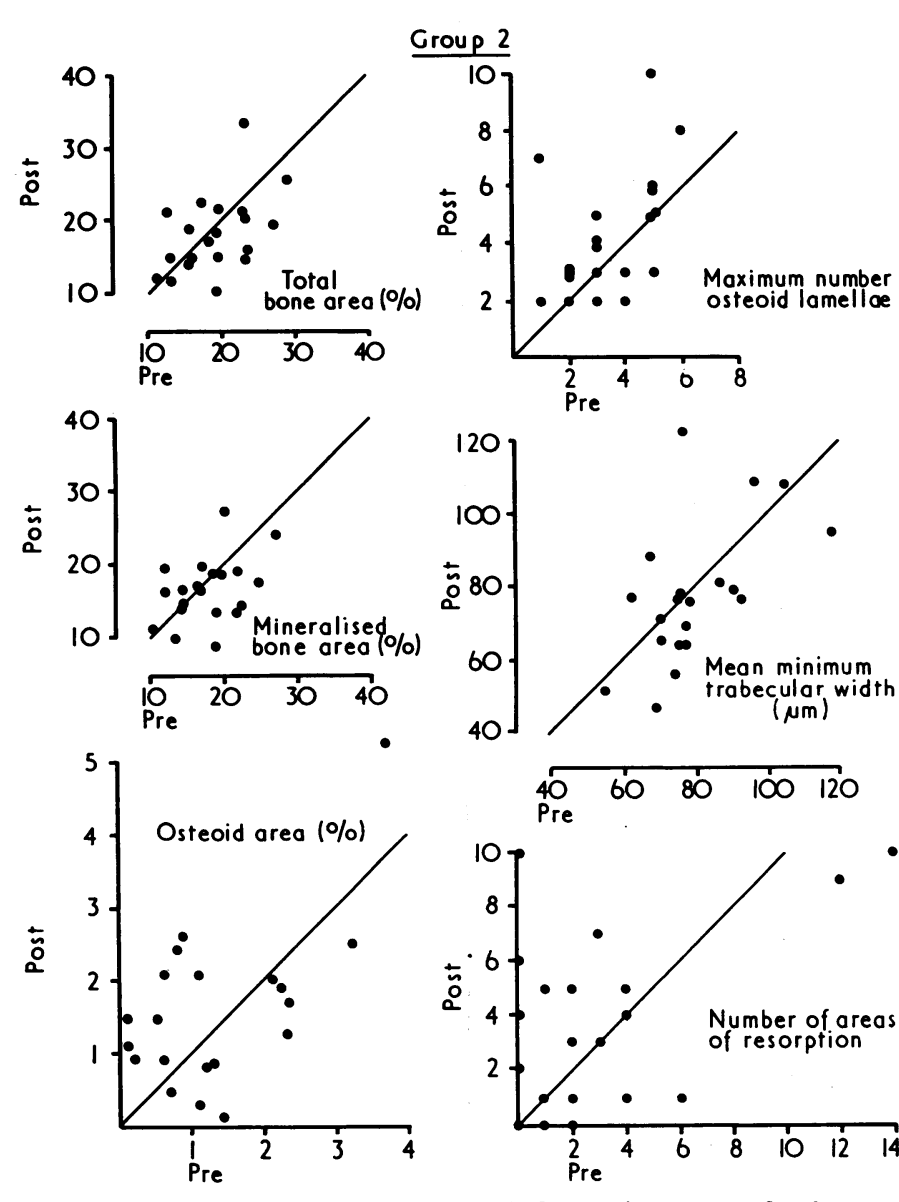

FIG. 2-Group 2. Results of bone biopsy before and one year after haemodyalysis. Each point represents one patient.

\section{Discussion}

Previous workers investigating bone disease in haemodialysed patients with chronic renal failure have dealt with the histological findings in separate groups of undialysed and dialysed patients, rather than the changes in individual patients from the start of dialysis (Kim et al., 1968; Jowsey et al., 1969; Ritz et al., 1971). It has been suggested and denied that dialysis may cause a specific form of bone disease. This is a difference of opinion which is best resolved by sequential biopsy studies in individual patients; although there is no way of determining what would have happened to the bones of a patient if he had not been dialysed.

Our methods of tissue preparation and interpretation are similar to those used elsewhere (Garner and Ball, 1966; Woods et al., 1968; Woods et al., 1972). Certain errors are inevitablefor instance, the differences in thickness of thin undecalcified sections can lead to an artefact in the measurement of bone and osteoid area (Dunnill, 1968). Observer error and variation within the iliac crest may mask small differences between individual biopsy specimens (Byers and Smith, 1971). Samples of the iliac crest or of any other bone may not be representative of the bone in the whole skeleton (Dunnill et al., 1969), but it is the only practical and accessible region for frequent sampling and normal data are available.

In this study the osteoid area increased and mineralized bone decreased during dialysis, and these changes were more pronounced in the first year of treatment than subsequently.

\section{INCREASED OSTEOID}

Increase in osteoid area might relate to excessive growth of bone matrix rather than to a failure of mineralization of normal amounts of matrix (Harris and Heaney, 1969). However, the number of osteoid lamellae is not increased in states of osteoid overproduction (Woods et al., 1968). We therefore used a measurement of osteoid thickness as an additional index of mineralization defect and to define osteomalacia. By using the criterion of five or more unmineralized osteoid lamellae (Woods et al., 1968) seven patients in group 1 developed this lesion in the first year of dialysis. Once established osteomalacia did not heal unless associated with osteitis fibrosa. We interpret this change from osteitis fibrosa with osteomalacia to osteitis fibrosa alone as the expected natural progression of renal osteodystrophy deduced from study of undialysed patients (Stanbury and Lumb, 1966).

The increase in mean osteoid area from the first biopsy specimens in group 1 to the second specimens in group 2, and the further rise in the number of osteoid lamellae, is an overall indication of progressive dissociation between the processes of matrix production and mineralization during dialysis treatment. Changes of osteomalacia can occur in undialysed patients, and haemodialysis cannot be incriminated as a cause of a specific bone disease on a basis of increased osteoid alone.

\section{LOSS OF MINERALIZED BONE}

We have described loss of mineralized matrix outweighing the rise in osteoid to give reduction of total bone mass in some patients to within the osteoporotic range. In contrast, in undialysed uraemic bone disease bone area counts tend to be higher than normal unless other causes of osteoporosis coexist. With reference to a normal lower limit of total bone area of $12 \%$ described by other authors using simil ır techniques (Garner and Ball, 1966) none of our patients had osteoporosis before dialysis, but it did develop after the start of treatment.

The measurement of minimum trabecular width was based on an observation that haemodialysed patients have significant narrowing of bone trabeculae in their cancellous bone (Siddiqui and Kerr, 1971). The fall in mean minimum trabecular width is further confirmation that bone loss occurred during the course of dialysis treatment.

Although some workers regard bone loss as a specific complication of dialysis therapy (Freeman et al., 1967; Kleeman et al., 1970; Siddiqui and Kerr, 1971) there is evidence that in the terminal stages of undialysed chronic renal failure bone mass tends to fall with the rise in plasma calcium and phosphorus (Stanbury, 1971), though there are no sequential data available to confirm this in individual patients.

Thus neither loss of bone nor increased volume of unmineralized osteoid can be regarded as specific effects of long-term haemodialysis but only of advanced uraemia.

\section{BONE RESORPTION}

No consistent pattern of change in the number of resorptive areas in sequential biopsy specimens could be discerned (see Figs. 1 and 2). While a patient with a larger number of resorptive areas than normal could progress to osteitis fibrosa, some reverted to normal. This may have been due to the fluctuating plasma concentration of factors known to modify osteoclastic activity, such as parathyroid hormone and phosphate (Raisz and Niemann, 1969). It was not unexpected that established osteitis fibrosa-representing the maximum degree of parathyroid gland autonomy-should fail to improve with regular dialysis treatment. Less degrees of parathyroid overactivity may have been suppressed by the "optimum" dialysate and plasma calcium (Fournier et al., 1971) and magnesium levels.

Our serial studies have therefore shown that conventional renal osteodystrophy can progress in dialysed patients, but a less familiar tendency to develop osteoporosis may occur. Other workers have described a combination of osteoporosis and osteomalacia as "osteopenic osteodystrophy" in dialysed patients (Stanbury, 1969), but the evidence that dialysis causes specific progressive bone changes has been mainly clinical 
(Siddiqui and Kerr, 1971). Histological methods have been only partly quantitative and serial biopsy specimens have not been obtained. Ellis and Peart (1971) emphasized in their description of "Newcastle dialysis bone disease" that in the course of time on dialysis loss of bone and defective mineralization become more severe, whereas osteitis fibrosa diminishes. Our results differ in this respect, though the incidence of osteitis fibrosa was low in our study, perhaps because the incidence of predialysis osteodystrophy in general is lower in Oxford than in Newcastle.

The conversion of vitamin $D$ to its active metabolite 1,25 dihydroxycholecalciferol is believed to occur specifically in the kidney (Fraser and Kodicek, 1970). Binephrectomized patients might be expected, therefore, to show evidence of a greater susceptibility to osteomalacia than other dialysed patients. In this series three patients were binephrectomized. Osteomalacia was observed in all three before nephrectomy, but progress of bone disease thereafter could not be distinguished from the pattern observed in un-nephrectomized dialysed patients. Indeed, in one anephric patient vitamin D treatment was followed by the appearance of osteitis fibrosa and healing of osteomalacia.

The cause of bone loss, possibly beginning in the terminal phases of chronic renal failure and certainly extending into the period of dialysis, in conjectural. Immobilization may be very important, since the observed changes were maximal in the first year of dialysis treatment when some patients spent long periods in hospital. In our series bone loss was apparently not influenced by parathyroidectomy (four patients), and it is probable that the parathyroids have no important role in the development of osteoposoris in dialysed patients (Harrison, 1968).

Unidentified factors in tap-water removed by deionizers probably contribute to osteomalacia and may be responsible for the pronounced regional variations in the incidence of "dialysis bone disease" (Posen et al., 1972).

We acknowledge the help of Dr. F. W. Wadia and Dr. G. D. Nicholson with the bone biopsies and thank the patients in this study for their willing co-operation.

\section{References}

Bishop, M. C., Ledingham, J. G. G., Oliver, D. O., and Smith, R. (1971). Proceedings of Eighth Congress of the European Dialysis and Transplant Association, p. 122. London, Pitman Medical.

Byers, P. D., and Smith, R. (1971). Quarterly fournal of Medicine, 40, 471. Dixon, W. J., and Massey, F. J. (1951). Introduction to Statistical Analysis, p. 16. New York, McGraw Hill.

Dunnill, M. S. (1968). In Recent Advances in Clinical Pathology, ed. S. C. Dyke, Series 5, p. 401. London, Churchill.

Dunnill, M. S., Anderson, J. A., and Whitehead, R. (1969). Fournal of Pathology and Bacteriology, 94, 275.

Ellis, H. A., and Peart, K. M. (1971). Nephron, 8, 402.

Follis, R. H., and Jackson, D. (1943). Bulletin of the fohns Hopkins Hospital, 72,232 .

Fournier, A. E., Arnaud, C. D., Johnson, W. J., Taylor, W. F., and Goldsmith, R. S. (1971). Fournal of Clinical Investigation, 50, 599.

Fraser, D. R., and Kodicek, E. (1970). Nature, 228, 769.

Freeman, R. B., Maher, J. F., O'Connell, J. M. B., and Schreiner, G. E. (1967). In Proceedings of Third International Congress of Nephrology, ed. G. Schreiner, vol. 3, p. 316. New York, Karger.

Garner, A., and Ball, J. (1966). Fournal of Pathology and Bacteriology, $91,545$.

Harris, W. H., and Heaney, R. P. (1969). New England fournal of Medicine, 280,193 .

Harrison, A. R. (1968). Proceedings of Fifth Congress of the European Dialysis and Transplant Association, p. 404. Amsterdam, Excerpta Medica.

Jowsey, J., Coburn, J. W., Massry, S. G., and Kleeman, C. R. (1969). Archives of Internal Medicine, 124, 539.

Katz, A. I., Hampers, C. L., and Merrill, J. P. (1969). Medicine, 48, 333.

Kaye, M., Chatterjee, G., and Cohen, G. F. (1969). Proceedings of Fourth International Congress of Nephrology, 3, 151 .

Kim, D., et al. (1968). Transactions of the American Society for Artificial Internal Organs, 14, 367.

Kleeman, C. R., Massry, S. G., Coburn, J. W., and Popovtzer, M. M. (1970). Clinical Orthopaedics, 86, 210.

Kyle, L. H. (1969). Annual Review of Medicine, 20, 259.

Pendras, J. P. (1969). Archives of Internal Medicine, 124, 312.

Pendras, J. P., and Erickson, R. V. (1966). Annals of Internal Medicine, 64, 293.

Posen, G. A., et al. (1972). Paper read to Association of Physicians of Great Britain and Ireland, 24 March.

Raisz, L. G., and Niemann, I. (1969). Endocrinology, 85, 446

Ritz, E., Krempien, B., Kuhns, H., and Henck, F. (1971). Israel fournal of Medical Science, 7, 520.

Siddiqui, J., and Kerr, D. N. S. (1971). British Medical Bulletin, 29, 153. Stanbury, S. W. (1969). Fournal of Bone and foint Surgery, 51B, 576.

Stanbury, S. W. (1971). In Phosphate et Metabolisme Phosphocalique, ed. D. J. Hioco, p. 187. Paris, Sandoz.

Stanbury, S. W., and Lumb, G. A. (1966). Quarterly fournal of Medicine, 35,1 .

Williams, J. A., and Nicholson, G. I. (1963). Lancet, 1, 1408.

Woods, C. G., Paterson, C. R., Morgan, D. B., and Gossmann, H. H (1968). Fournal of Pathology and Bacteriology, 95, 441.

Woods, C. G., Bishop, M. C., and Nicholson, G. D. (1972). Fournal of Pathology. In press.

\title{
The Risk of Rh Isoimmunization in Ruptured Tubal Pregnancy
}

\author{
J. KATZ, R. G. MARCUS
}

British Medical fournal, 1972, 3, 667-669

\section{Summary}

In $9(24 \%)$ out of 38 African women who had suffered a ruptured tubal pregnancy significant numbers of fetal erythrocytes (5 or more per 150,000 maternal cells) were found in the maternal circulation. This is a higher incidence than occurs after abortion and indicates that rupture of a tubal pregnancy is a potential source of $R h$ isoimmunization. The finding of fetal cells in the peritoneal cavity suggests that this is the main source of the fetal blood found in the maternal circulation. At opera-

\footnotetext{
University of the Witwatersrand and South African Institute for Medical Research, Johannesburg, South Africa

J. KATZ, M.B., F.C.PATH. (S.A.), Senior Haematologist

University of the Witwatersrand, Johannesburg, South Africa R. G. MARCUS, M.B., M.R.C.o.G., Registrar in Obstetrics and Gynaecology
}

tion on Rh-negative patients with ruptured tubal pregnancies, therefore, complete removal of the peritoneal blood should be attempted and the blood recovered should never be transfused into the patient, who should always receive prophylactic $\mathrm{Rh}$ immunoglobulin.

\section{Introduction}

The prophylactic administration of $\mathrm{Rh}$ immunoglobulin is an accepted method of prevention of $\mathrm{Rh}$ isoimmunization. Clinical trials have shown that more than $90 \%$ of $\mathrm{Rh}$-negative primiparae are protected if the recommended dose of $\mathrm{Rh}$ immunoglobulin is injected within 72 hours of the birth of a Rh-positive baby (Combined Study, 1971; Woodrow et al., 1971). In addition to full-term pregnancy abortion has been implicated as a cause of $\mathrm{Rh}$ isoimmunization (Matthews and Matthews, 1969; Katz, 1969), and it is recommended that all Rh-negative women who have aborted should receive $\mathrm{Rh}$ immunoglobulin prophylactically (Freda et al., 1970; Murray and Barron, 1971). 